\title{
Organic Anion Transporting Polypeptide-Mediated Hepatic Uptake of Glucuronide Metabolites of Androgens
}

\author{
Cindy Yanfei Li, Anshul Gupta, Zsuzsanna Gáborik, Emese Kis, and Bhagwat Prasad
}

Department of Pharmaceutics, University of Washington, Seattle, Washington (C.Y.L.); Amgen Research, Department of Pharmacokinetics and Drug Metabolism, Cambridge, Massachusetts (A.G.); SOLVO Biotechnology, Budapest, Hungary (Z.G., E.K.); Department of Pharmaceutical Sciences, Washington State University, Spokane, Washington (B.P.)

Received February 24, 2020; accepted June 11, 2020

\section{ABSTRACT}

We previously established that androgen glucuronides are effluxed by multidrug resistance-associated proteins 2 and 3 . However, no data exist on the mechanism of hepatic uptake of these metabolites. The first goal of this study was to explore the role of hepatic uptake transporters and characterize transport kinetics of glucuronides of testosterone (TG), dihydrotestosterone (DHTG), androsterone (AG), and etiocholanolone (EtioG) using cell lines overexpressing organic anion transporting polypeptides (OATP1B1, OATP1B3, and OATP2B1). Using a quantitative proteomics-guided approach, we then estimated the fractional contribution of individual OATPs in hepatic uptake of these glucuronides. The transport screening assays revealed that the glucuronides were primarily taken up by OATP1B1 and OATP1B3. The $K_{\mathrm{m}}$ values for OATP1B1-mediated uptake were low for EtioG $(6.2 \mu \mathrm{M})$ as compared with AG, TG, and DHTG $\left(46.2,56.7\right.$, and $71.3 \mu \mathrm{M}$, respectively), whereas the $K_{\mathrm{m}}$ value for OATP1B3-mediated uptake for EtioG, AG, DHTG, and TG were 19.8, 29.3, 69.6, and 110.4 $\mu \mathrm{M}$, respectively. Both OATP1B1 and OATP1B3 exhibited the highest transport rate toward AG as compared with other glucuronides. When adjusted for the transporter abundance in human livers, EtioG and DHTG were predicted to be transported by both OATP1B1 and OATP1B3, whereas TG and AG were preferentially ( $>68 \%$ ) transported by OATP1B3. Collectively, this report elucidates the mechanisms of hepatic uptake of androgen glucuronides. Perturbation of these processes by genetic polymorphisms, disease conditions, or drug interactions can lead to changes in enterohepatic recycling of androgens. TG and AG can be further investigated as potential biomarkers of OATP1B3 inhibition.

\section{SIGNIFICANCE STATEMENT}

This is the first study to elucidate the mechanism of hepatic uptake of androgen glucuronides and estimate the fractional contribution of individual OATPs using quantitative proteomics. Our results show that both OATP1B1 and OATP1B3 are responsible for the hepatic uptake of major circulating testosterone glucuronides. The apparent higher selectivity of OATP1B3 toward testosterone glucuronide and androsterone glucuronide can be leveraged for establishing these metabolites as clinical biomarkers of OATP1B3 activity.

\section{Introduction}

Testosterone is crucial for normal physiologic growth and health, including development of male sexual characteristics, muscle mass, maintaining adequate red blood cells, bone growth, and a sense of well-being. Testosterone deficiency or hypogonadism is a growing problem affecting over 20 million men in the United States and is most prevalent in aging men (McBride et al., 2016; Traish, 2016; Ugwu and Ikem, 2018). Testosterone replacement therapy (TRT) is the front-line

This project was supported by Amgen. Solvo Biotechnology provided the transporter-expressing cell lines for transporter study. A.G. is an employee of Amgen, and Z.G. and E.K. are the employees of Solvo Biotechnology. The experimental work done by B.P. was conducted at the University of Washington prior to moving to Washington State University.

https://doi.org/10.1124/mol.120.119891.

S This article has supplemental material available at molpharm. aspetjournals.org treatment option for hypogonadism and offers substantial benefits, such as improved libido, mood, cognition, muscle mass, bone density, and red blood cell production (Schlich and Romanelli, 2016). However, high interindividual variability in systemic testosterone levels and its outcomes generally leads to an uncertain risk-to-benefit ratio of TRT (Bhasin et al., 2006, 2010; Bhasin and Matsumoto, 2010).

Although benefits of TRT are more subjective, TRT is associated with side effects such as polycythemia, myocardial infarction, heart failure, stroke, depression, and liver toxicity, as a result of which the US Food and Drug Administration issued black-box warning on using testosterone products (Bhasin et al., 2006, 2010; Bhasin and Matsumoto, 2010; Schlich and Romanelli, 2016) (https://www.fda.gov/drugs/ postmarket-drug-safety-information-patients-and-providers/ testosterone-information). Furthermore, testosterone does not directly cause prostate cancer (Heikkilä et al., 1999) but has

ABBREVIATIONS: $\mathrm{AG}$, androsterone glucuronide; $\mathrm{Cl}$, confidence interval; $C L_{\text {int }}$, intrinsic clearance; DDI, drug-drug interaction; $\mathrm{DHEAS}$, dehydroepiandrosterone-sulfate; DHT, dihydrotestosterone; DHTG, dihydrotestosterone glucuronide; DMEM, Dulbecco's modified Eagle's medium; $E_{2} 17 \beta D G$, estradiol-17 $\beta$-glucuronide; $E_{3} S$, estrone-3-sulfate; EtioG, etiocholanolone glucuronide; $\mathrm{f}_{t}$, fractional contribution; HBSS, Hank's balanced salt solution; HEK, human embryonic kidney; LC-MS/MS, liquid chromatography tandem mass spectrometry; MDCK, MadinDarby canine kidney; MRP, multidrug resistance protein; OATP, organic anion transporting polypeptide; TG, testosterone glucuronide; TM-PPGT, total membrane protein per gram of liver tissue; TRT, testosterone replacement therapy; UGT, UDP-glucuronosyltransferase. 
been shown to accelerate prostate cancer development (Tenover, 1992) and worsen symptoms of benign prostatic hyperplasia (Jarvis et al., 2015). The most recent trial of the oral testosterone drug Lipocine failed to meet three secondary goals related to understanding the safety of higher testosterone levels in men due to issues in its pharmacokinetics $\left(C_{\max }\right)$ and risks of high blood pressure (https://www.reuters.com/ article/us-lipocine-fda/fda-rejects-lipocines-testosterone-drug-forthird-time-idUSKBN1XL1H4). Thus, high interindividual variability in systemic testosterone disposition and response in men presents a notable challenge in identifying not only those who will benefit from TRT but also those who may experience adverse events. As a result, only $\sim 5 \%$ of the total population of patients with hypogonadism in the United States are using TRT as a pharmacotherapy. Moreover, testosterone abuse is also common among athletes, and variability in testosterone disposition is associated with marked false-positive or false-negative detection of illicit use of testosterone (Saudan et al., 2006).

As a first step toward ensuring safer therapy and accurate detection of testosterone abuse, our laboratory focuses on investigation of factors that affect testosterone systemic exposure and renal elimination. Liver is the primary site of testosterone metabolism, and a substantial amount of testosterone conjugates are actively excreted in bile (West et al., 1951; Sandberg and Slaunwhite, 1956; Mauvais-Jarvis et al., 1968). However, about $90 \%$ of the intramuscular dose of testosterone is excreted in urine as glucuronic (40\%-80\%) and sulfuric (10\%-20\%) acid conjugates. We also observed that the serum concentration of testosterone glucuronide is 20- to 80-fold higher than testosterone after an oral dose (Basit et al., 2018). We then uncovered that testosterone and its active metabolite, dihydrotestosterone (DHT), are primarily metabolized to the hydrophilic testosterone glucuronide by a highly variable enzyme, UGT2B17, which is expressed in both liver and intestine with a minor contribution of UGT2B15 (Zhang et al., 2018). As these conjugates are hydrophilic and cannot passively diffuse across cell membranes (Alvarez et al., 2011; Brand et al., 2011; Patel et al., 2013; Zimmerman et al., 2013; González-Sarrías et al., 2014), they require active transporters to cross cell membranes. Indeed, we found that the intracellular testosterone, or DHT glucuronides, are effluxed by multidrug resistance proteins (MRP) 2 and 3 in liver and intestine into the bile or blood (Li et al., 2019). However, mechanisms of hepatic uptake of androgen glucuronides are still unknown.

Endogenous glucuronides such as bilirubin and vitamin D glucuronides are the known substrates of OATPs (Chu et al., 2017); therefore, the goal of this study was to characterize uptake transport kinetics of glucuronides of testosterone, DHT, androsterone, and etiocholanolone using cell lines expressing hepatic OATPs (1B1, 1B3, and 2B1). Using a quantitative proteomics-guided approach ( $\mathrm{Li}$ et al., 2019), we then estimated the fractional contribution $\left(f_{t}\right)$ of individual OATPs in hepatic uptake of the androgen glucuronides.

\section{Materials and Methods}

Chemicals and Reagents. Testosterone glucuronide (TG), androsterone glucuronide (AG), dihydrotestosterone glucuronide (DHTG), and the corresponding deuterated stable-labeled internal standards TG-d3, AG-d4, and DHTG-d3 were purchased from Cerilliant Corporation
(Round Rock, TX). Etiocholanolone glucuronide (EtioG) standard was purchased from Steraloids (Newport, RI). Human embryonic kidney (HEK) 293 cells stably expressing the human OATP1B1 or OATP1B3, Madin-Darby canine kidney (MDCK) cells stably transfected with human OATP2B1, and their corresponding empty vector-transduced (thereafter referred as mock-transduced cells, which are treated with transfection reagents only and used as negative controls) or nontransfected cells were provided by Solvo Biotechnology (Budapest, Hungary). Poly-D-lysine-coated 24-well plates were obtained from BD Sciences (Franklin Lakes, NJ). Dithiothreitol, iodoacetamide, bicinchoninic acid assay kit, bovine serum albumin, membrane protein extraction kit, and trypsin digestion reagents were obtained from Thermo Fisher Scientific (Rockford, IL). The synthetic lightand heavy-labeled peptides for OATP1B1, OATP1B3, and OATP2B1 were purchased from New England Peptides (Boston, MA) and Thermo Fisher Scientific, respectively. Dulbecco's modified Eagle's medium (DMEM), FBS, penicillin and streptomycin solution, and Hank's balanced salt solution (HBSS) with calcium and magnesium were obtained from Invitrogen (Carlsbad, CA). All other chemicals and reagents, unless indicated otherwise, were purchased from Sigma-Aldrich (St. Louis, MO).

Functional Characterization of OATP Cell Lines. The stably overexpressing cell lines were maintained in DMEM supplemented with $10 \% \mathrm{FBS}$, penicillin $(100 \mathrm{U} / \mathrm{ml})$, and streptomycin $(100 \mathrm{mg} / \mathrm{ml})$. For HEK293 cells expressing OATP1B1 or OATP1B3, $3 \mu \mathrm{g} / \mathrm{ml}$ puromycin was used for selection. For functional characterization of OATP cell lines, 100,000 cells per well were seeded into poly-D-lysinecoated 96-well plates from the corresponding cell line and were incubated for 24 hours at $37^{\circ} \mathrm{C}$ with $5 \% \mathrm{CO}_{2}$ before the experiments. Time dependence experiments were carried out to determine the linear range of the transport with relevant probe substrate estradiol-17 $\beta$ glucuronide $\left(\mathrm{E}_{2} 17 \beta \mathrm{DG}\right)$ and estrone-3-sulfate $\left(\mathrm{E}_{3} \mathrm{~S}\right)$. For concentration dependence experiments, cells were incubated with increasing concentrations of their probe substrate to determine the kinetic parameters of transport $\left(K_{\mathrm{m}}\right.$ and $\left.V_{\max }\right)$ (data not shown). Experiments were carried out at $37^{\circ} \mathrm{C}$, and mock-transduced HEK293 or MDCKII cells were used as controls. After cell lysis with $0.1 \mathrm{M}$ sodium hydroxide, scintillation cocktail mix was added to the wells, and intracellular accumulation of the probe substrate was analyzed with liquid scintillation (MicroBeta2 or MicroBeta TriLux; PerkinElmer, Waltham, MA).

Transporter-expressing cells and corresponding mock-transduced controls were seeded on untreated (if MDCKII-derived) or poly-D-lysinetreated (if HEK293-derived) 96-well tissue culture plates at a density of $1 \times 10^{5}$ cells per well for 24 hours. Before the experiments, the cells were washed three times with prewarmed Krebs-Henseleit (or HBSS for HEK293-OATP1B3) buffer and then preincubated with KrebsHenseleit (or HBSS) buffer at $37^{\circ} \mathrm{C}$ for 10 minutes. The reactions were started with prewarmed buffer containing both cold and radiolabeled probe substrate in appropriate concentration $\left(0.2 \mu \mathrm{M} \mathrm{E}_{3} \mathrm{~S}\right.$ for OATP2B1, $1 \mu \mathrm{M} \mathrm{E}_{2} 17 \beta \mathrm{DG}$ for OATP1B1 and OATP1B3) and then incubated for 2 minutes. Uptake was terminated by rinsing twice with ice-cold assay buffer, and cells were lysed with $0.1 \mathrm{M} \mathrm{NaOH}$. Radioactivity in cell lysates mixed with liquid scintillation cocktail (Ultima Gold XR; PerkinElmer) was measured with a MicroBeta2 microplate counter (PerkinElmer).

Uptake of Glucuronide Metabolites into HEK293-OATP1B1, HEK293-OATP1B3, and MDCKII-OATP2B1 Overexpressing Cell Lines. The stably overexpressing cell lines were maintained in DMEM supplemented with $10 \% \mathrm{FBS}$, penicillin $(100 \mathrm{U} / \mathrm{ml})$, and streptomycin $(100 \mathrm{mg} / \mathrm{ml})$. For HEK293 cells expressing OATP1B1 or OATP1B3, $3 \mu \mathrm{g} / \mathrm{ml}$ puromycin was used for selection. Cells were plated on poly-D-lysine-coated 24 -well plates at a density of $5 \times 10^{5}$ cells per well for 24 hours, and then $5 \mathrm{mM}$ sodium butyrate was added to culture medium, and the culture was continued for another 24 hours to induce OATP expression. Before the uptake experiment, the cells were washed three times with prewarmed HBSS buffer and then preincubated with HBSS buffer at $37^{\circ} \mathrm{C}$ for 10 minutes. The initial screening was 
conducted with $10 \mu \mathrm{M}$ substrate at $37^{\circ} \mathrm{C}$ for 5 minutes (over which the uptake was found linear, data not shown). The incubation was terminated by aspirating the remaining incubation solution, followed by washing the cells three times with ice-cold HBSS buffer. Subsequently, the cells were lysed in acetonitrile containing stable isotope-labeled internal standards (Supplemental Table 1). The amount of TG, AG, EtioG, or DHTG accumulated in the cells was quantified by LC-MS/MS [SCIEX Triple Quadrupole 6500 system (Framingham, WA) coupled to an ACQUITY ultra-performance liquid chromatography system (Waters Technologies, Milford, MA)], as described previously (Li et al., 2019). Five microliters of each sample was injected to the column (ACQUITY ultra-performance liquid chromatography HSS T3, $1.8 \mu \mathrm{m}$, C18 100A; $100 \times 2.1 \mathrm{~mm}$; Waters), with a gradient mobile phase $(0.3 \mathrm{ml} / \mathrm{min})$ consisting of $0.1 \%$ formic acid in water (A) and $0.1 \%$ formic acid in acetonitrile (B): 0-0.4 minutes, $30 \% \mathrm{~B}$; 0.4-1.8 minutes, $30 \%-95 \% \mathrm{~B}$; 1.8-2.2 minutes, $95 \% \mathrm{~B}$; $2.2-2.3$ minutes, $95 \%-30 \% \mathrm{~B}$; 2.3-4 minutes, $30 \%$ B. The detailed LC-MS/MS parameters for quantification of glucuronides are described previously ( $\mathrm{Li}$ et al., 2019).

The transport kinetic analyses were carried out for OATP1B1 and OATP1B3 only based on their activities shown as in the initial screening (Fig. 1) using a substrate concentration range from 1 to $500 \mu \mathrm{M}$. All incubations for kinetic studies were performed for 5 minutes in triplicates ( $n=3$, Supplemental Fig. 1). In parallel, cells grown under the same conditions were lysed with $0.05 \mathrm{ml}$ of $2 \%$ SDS, and protein concentrations of cell lysates were determined by bicinchoninic acid assay protein assay kit. The accumulation or uptake of studied glucuronides in cells was normalized to protein content of the cells.

Quantification of Uptake Transporters in Overexpressing Cells and Human Livers by Quantitative Proteomics. Transporter abundance was quantified using proteomics protocols optimized in our laboratory (Prasad et al., 2016). Briefly, cell homogenates $(80 \mu \mathrm{g})$ were incubated with $10 \mu \mathrm{l}$ of dithiothreitol $(250 \mathrm{mM}), 30 \mu \mathrm{l}$ of ammonium bicarbonate buffer $(100 \mathrm{mM}, \mathrm{pH} 7.8), 20 \mu \mathrm{l}$ of bovine serum albumin $(0.02 \mathrm{mg} / \mathrm{ml})$, and $10 \mu \mathrm{l}$ of human serum albumin $(10 \mathrm{mg} / \mathrm{ml})$ at $95^{\circ} \mathrm{C}$ for 10 minutes, followed by the addition of $20 \mu l$ of iodoacetamide $(500 \mathrm{mM})$, and incubated at room temperature for 30 minutes in the dark. The samples were then treated with ice-cold methanol $(0.5 \mathrm{ml})$, chloroform $(0.1 \mathrm{ml})$, and water $(0.4 \mathrm{ml})$ and centrifugated at $16,000 \mathrm{~g}$ for 5 minutes at $4^{\circ} \mathrm{C}$. The pellet was washed once with ice-cold methanol $(0.5 \mathrm{ml})$, centrifuged at $8000 \mathrm{~g}$ for 5 minutes, and resuspended with $60 \mu \mathrm{l}$ of ammonium bicarbonate buffer $(50 \mathrm{mM})$. Finally, the protein sample was digested with $20 \mu \mathrm{l}$ of trypsin at 1:10 trypsin:protein ratio $(\mathrm{w} / \mathrm{w})$ and incubated for 16 hours at $37^{\circ} \mathrm{C}$ with mixing at $300 \mathrm{rpm}$. The digestion reaction was quenched by $20 \mu \mathrm{l}$ of chilled heavy internal standard (dissolved in $80 \%$ acetonitrile with $0.5 \%$ formic acid) and centrifuged at $4000 \mathrm{~g}$ for 5 minutes at $4^{\circ} \mathrm{C}$. For each sample, $5 \mu \mathrm{l}$ of the supernatant was injected into the LC-MS/MS system for analysis using the same SCIEX instrument discussed above. The mobile phases $(0.3 \mathrm{ml} / \mathrm{min})$ consisted of $0.1 \%$ formic acid in water (A) and $0.1 \%$ formic acid in acetonitrile (B). The gradient program for determining transporter abundances in cells was as follows: 0-4 minutes, 3\% B; 4-8 minutes, $3 \%-13 \%$ B; 8-18 minutes, $13 \%-30 \%$ B; 18-20.5 minutes, $30 \%-35 \%$ B; 20.5-21.1 minutes, $35 \%-60 \%$ B; $21.1-23.1$ minutes, $60 \%-80 \% \mathrm{~B}$; 23.1-23.2 minutes, $80 \%-3 \%$ B; $23.2-27.0$ minutes, $3 \%$ B. All samples were digested and processed in triplicate. The pooled total membrane fraction of human liver $(n=36)$ samples was available in our laboratory from previous studies (Prasad et al., 2016) by using as an internal biologic control. The surrogate peptides of OATP1B1, OATP1B3, and OATP2B1 are listed in Supplemental Table 1. The pooled total membrane sample isolated from liver tissue with known transporter abundance was used as a calibrator for estimation of abundances of individual transporters in overexpressing cells (Bhatt and Prasad, 2018).

For both the overexpression system and liver tissue, the total membrane proteins were extracted, and the values were used for normalization. In this way, the protein abundance of individual

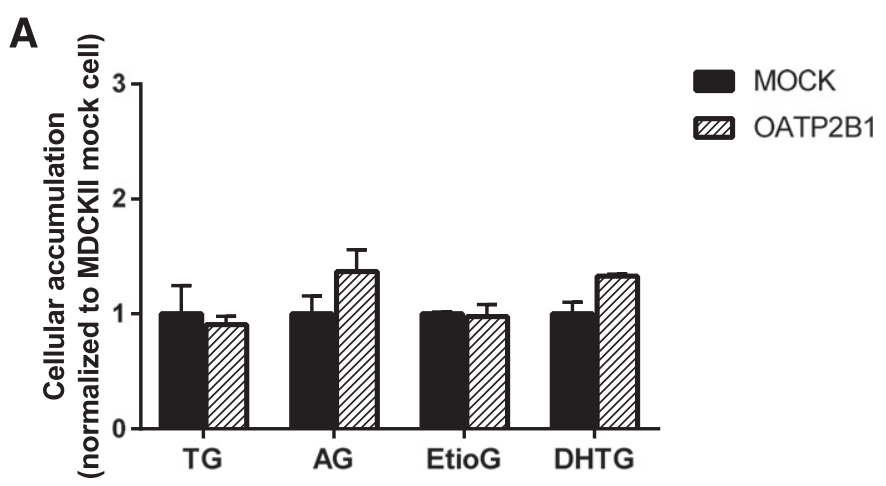

B

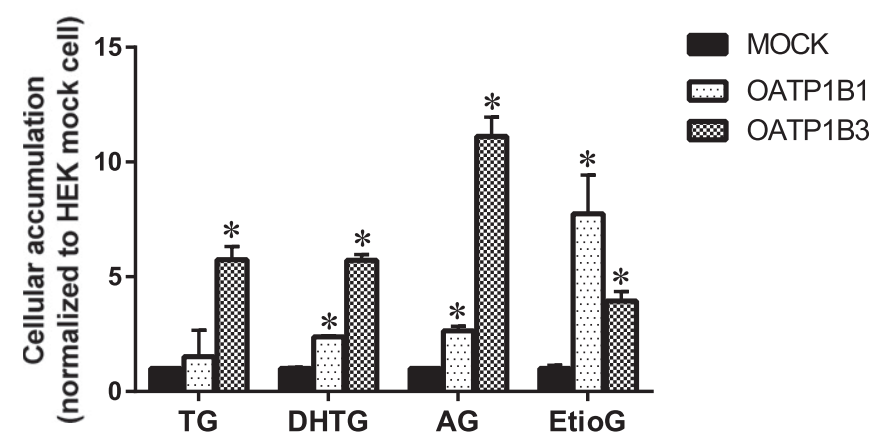

Fig. 1. Active uptake of major testosterone glucuronide metabolites (TG, DHTG, AG, and EtioG) in OATP2B1-overexpressing MDCKII cells (A) and OATP1B1- or OATP1B3-overexpressing HEK293 cells (B). The passive diffusion data were generated in corresponding MDCKII or HEK293 control cells (MOCK). The uptake experiment was performed by incubating $10 \mu \mathrm{M}$ test substrate (final concentration) for 5 minutes. The cellular accumulation of the studied glucuronides in OATP-overexpressing cells was calculated by subtracting the passive diffusion data (MOCK) from the total uptake in the OATP-overexpressing cells. The differences in the cellular accumulation (total minus passive) of the studied glucuronides were analyzed using one-way ANOVA followed by Dunnett's multiple comparison test (GraphPad Prism 7.00). An asterisk (*) denotes $P<0.05$. All incubations for uptake studies were performed in triplicates $(n=3)$.

transporter, as in per milligram of total membrane proteins, could be compared. Because of the technical difficulties, the plasma membrane fraction was not separated, but instead the total transporter abundance in whole liver tissue was calculated, which is more accepted in pharmacokinetic predictions (Prasad et al., 2018, 2019). The presence or absence of nonparenchymal cells does not affect the scaling, because only the total membrane protein per gram of tissue was considered as a scaling factor, which remains similar for all the transporters in the given tissue.

Data and Statistical Analyses. The OATP-mediated uptake is calculated by subtracting the total uptake in HEK-MOCK (saturable plus nonsaturable) from that in HEK-OATP cells (nonsaturable) prior to data fitting. The $K_{\mathrm{m}}$ and $V_{\max }$ values of uptake transport were calculated by fitting a Michaelis-Menten equation using GraphPad Prism software (La Jolla, CA). The uptake activity of studied glucuronides was calculated by normalizing the measured cellular accumulation amount to the incubation time and protein content (picomoles per minute per milligram protein). The intrinsic clearance of glucuronide transport in overexpressing cell lines $\left(C L_{\text {int,cells }}\right.$, microliters per minute) was scaled to that in human liver using transporter expression data $\left(\mathrm{E}_{\text {tissue,total }} / \mathrm{E}_{\text {cells }}\right.$, eq. 1), as described previously (Li et al., 2019). For either OATP1B1 or OATP1B3, the $\mathrm{E}_{\text {tissue,total }}$ was calculated by multiplying picomole transporter abundance per milligram of protein with total membrane protein per gram of liver tissue (TM-PPGT, picomole protein per gram of liver tissue $)$ and with liver weight $(1.6 \mathrm{~kg})$ 
(Table 2). The TM-PPGT value was determined experimentally for human liver in-house (Prasad et al., 2016).

$$
\begin{gathered}
C L_{\text {int }}=\frac{V_{\text {max }, \text { cells }}}{K_{m, \text { cells }}} \times \frac{E_{\text {tissue, total }}}{E_{\text {cells }}} \\
C L_{\text {total }}=C L_{\text {int }, \text { OATP1B1 } 1}+C L_{\text {int }, \text { OATP } 1 B 3} \\
f_{t}=\frac{C L_{\text {int }, \text { transporter }}}{C L_{\text {total }}}
\end{gathered}
$$

The $C L_{\text {int }}$ for OATP1B1 or OATP1B3 was used to estimate the total CL using eq. 2 , which then allowed derivation of the fractional contribution $\left(f_{t}\right)$ of each transporter (OATP1B1 or OATP1B3) for glucuronide transport in vivo by eq. 3 . For this scaling approach, we assumed that in both in vivo or in cell system, the transporters are primarily expressed in the plasma membrane.

\section{Results}

Functional Characterization of OATP-Overexpressing Cell Lines. Kinetic parameters of transporter-mediated uptake in HEK293 and MDCKII cells expressing the corresponding OATP transporters were determined using their relevant endogenous substrates. As expected, marked transportermediated uptake of the probe substrate $\left(\mathrm{E}_{2} 17 \beta \mathrm{DG}\right.$ or $\left.\mathrm{E}_{3} \mathrm{~S}\right)$ was observed in HEK293 and MDCKII cells expressing the corresponding OATP transporters compared with control cells (Supplemental Table 2). The calculated transport rates were the following: $13.4 \mathrm{pmol} / \mathrm{min}$ per milligram total protein (OATP1B1 for $\mathrm{E}_{2} 17 \beta \mathrm{DG}$ ), $8.9 \mathrm{pmol} / \mathrm{min}$ per milligram total protein (OATP1B3 for $\mathrm{E}_{2} 17 \beta \mathrm{DG}$ ), and $1.6 \mathrm{pmol} / \mathrm{min}$ per milligram total protein (OATP2B1 for $\mathrm{E}_{3} \mathrm{~S}$ ).

OATP Mediated Transport Kinetics $\left(V_{\max }\right.$ and $\left.K_{\mathrm{m}}\right)$ of Androgen Glucuronides in Overexpressing Cell Lines. The initial screening results showed that TG, DHTG, AG, and EtioG were primarily transported by OATP1B1 or OATP1B3, but not by OATP2B1 (Fig. 1). The cellular accumulation of TG, DHTG, AG, and EtioG in OATP1B1 cells was approximately 1.5-, 2.4-, 2.6-, and 7.7-fold greater than that in MOCK control cells, respectively. Compared with MOCK control cells, OATP1B3 showed a much greater uptake activity toward TG (5.8-fold), DHTG (5.7-fold), and AG (10.8-fold). The cellular accumulation of EtioG by OATP1B3 was 3.9-fold greater than that in control cells (Fig. 1B).

EtioG and TG exhibited higher affinity for OATP1B1 with $K_{\mathrm{m}}$ values of 6.2 and $56.7 \mu \mathrm{M}$, respectively, as compared with OATP1B3, which showed $K_{\mathrm{m}}$ values of $19.8 \mu \mathrm{M}$ for EtioG and $110.4 \mu \mathrm{M}$ for TG. Similar affinity was observed for DHTG by OATP1B1 $\left(K_{\mathrm{m}}, 71.3 \mu \mathrm{M}\right)$ and OATP1B3 $\left(K_{\mathrm{m}}, 69.6 \mu \mathrm{M}\right)$, whereas AG was by OATP1B3 with a $K_{\mathrm{m}}$ of $29.3 \mu \mathrm{M}$ as compared with OATP1B1 $\left(K_{\mathrm{m}}, 46.2 \mu \mathrm{M}\right)$ (Fig. 2; Table 1$)$.

Comparison of Transporter Abundance in Tissue Versus Overexpressing Cell Line. In HEK293 overexpressing cell lines, the protein abundances of OATP1B1 and OATP1B3 were 6.9 and $7.4 \mathrm{pmol} / \mathrm{mg}$ protein, respectively, which were 1.9- and 5.0-fold higher than those in human liver tissue (Table 2). The protein abundance of OATP2B1 in the transfected MDCK-II cells was $4.25 \mathrm{pmol} / \mathrm{mg}$ protein (data not shown).

Fractional Contribution of OATP1B1 and OATP1B3 Based on the Transporter Abundance Data. In overexpressing cells when normalized by transporter abundance, OATP1B3 appeared to be the major contributor to the uptake of studied glucuronides, with the fractional contribution ranging from $66 \%$ to $89 \%$ (Fig. 3). Specifically, the $C L_{\text {int,cell }}$ values of OATP1B3 for AG, TG, DHTG, and EtioG were 7.9-, 5.2-, 2.4-, and 2.0-fold higher than that by OATP1B1, respectively (Table 2). When these data were normalized to transporter abundance in human liver tissues, about $68 \%-76 \%$ of TG and AG were transported by OATP1B3, whereas OATP1B1 and OATP1B3 contributed equally to the hepatic uptake clearance of DHTG and EtioG (Fig. 3).

\section{Discussion}

To our knowledge, this is the first study that elucidated the mechanisms of hepatic uptake of androgen glucuronides. We found that OATP1B3 is the major transporter that regulates hepatic uptake of TG and AG, whereas DHTG and EtioG are equally transported by OATP1B1 and OATP1B3. We have previously shown that MRP2 and MRP3 are the major transporters in the liver that facilitate cellular efflux of the androgen glucuronides (Li et al., 2019). In the intestine, MRP3 mediates the efflux of androgen glucuronides. Taken together with the current findings, it can be concluded that a majority of glucuronide metabolites of active androgen (e.g., TG and DHTG) are eliminated into the intestine through bile. The intestinal glucuronides can be deconjugated by gut bacterial $\beta$-glucuronidases and reactivate to active androgen for reabsorption (Fig. 4). These mechanisms thus work in tandem to increase half-life of active androgen in the body. Perturbation of any of these processes can lead to possible impact on androgen homeostasis.

The findings of this study are relevant to predict the effect of these processes in exogenously administered testosterone for hypogonadism. In the United States, 21.7 million men suffer from testosterone deficiency or hypogonadism. The condition is prevalent in aging men and is associated with symptoms including loss of libido, erectile dysfunction, anemia, diminished intellectual capacity, depression, lethargy, osteoporosis, and loss of muscle mass and strength. Although TRT is promising in treating hypogonadism and offers a wide range of benefits, it is associated with severe idiosyncratic adverse events, including polycythemia, myocardial infarction, heart failure, stroke, depression, liver toxicity, and possible risk of prostate cancer. The US Food and Drug Administration has issued a black-box warning for TRT, and unfortunately, less than half of the men with hypogonadism in the United States receive TRT, likely because of the potential high risk-to-benefit ratio. The systemic testosterone levels and efficacy and safety of TRT can be affected by altered biosynthesis, absorption, metabolism, and/or excretion of testosterone and its active metabolite, DHT. Our data reported in this study suggest a potential role of polymorphic OATPs in regulating testosterone glucuronide uptake. These findings are also relevant to the regulation of androgen homeostasis and could partly explain variability in doping test results.

OATPs are highly polymorphic, and gene polymorphisms in OATP1B1 and OATP1B3 are associated with several clinical outcomes, including toxicity (Kalliokoski and Niemi, 2009). Notably, OATP1B1 c.521T $>$ C exhibits decreased uptake activity and is associated with increased risk of statin-induced myopathy, rhabdomyolysis, and hepatotoxicity (Link et al., 2008; Voora et al., 2009; Carr et al., 2013; Maeda, 2015). On the other hand, c.388A $>\mathrm{G}$ increases OATP1B1 function, causing decreased plasma concentration of pravastatin and other 
A
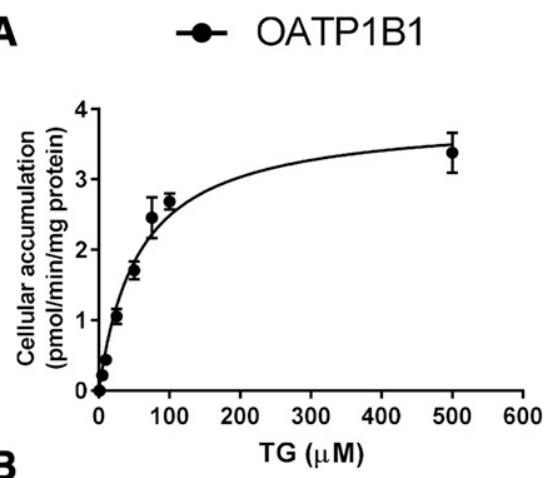

B

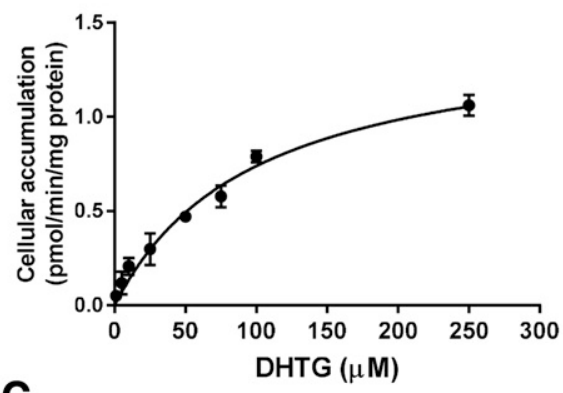

C
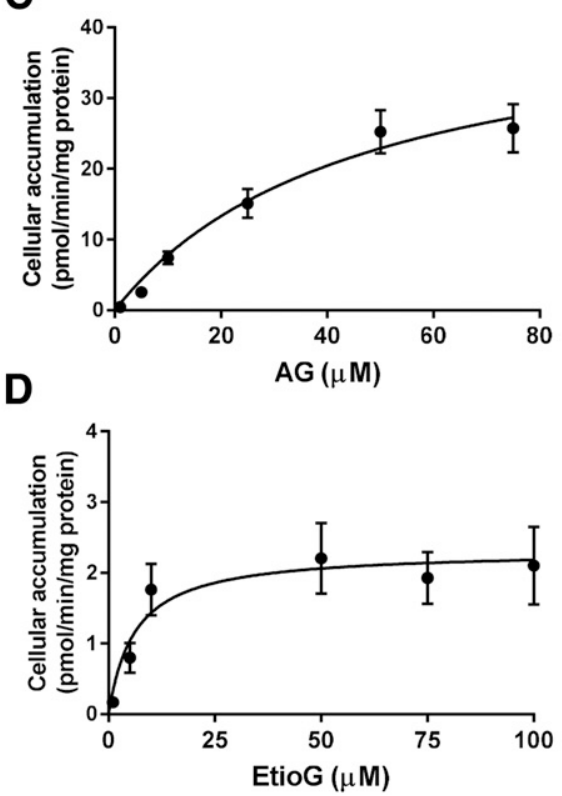

$\rightarrow$ OATP1B3
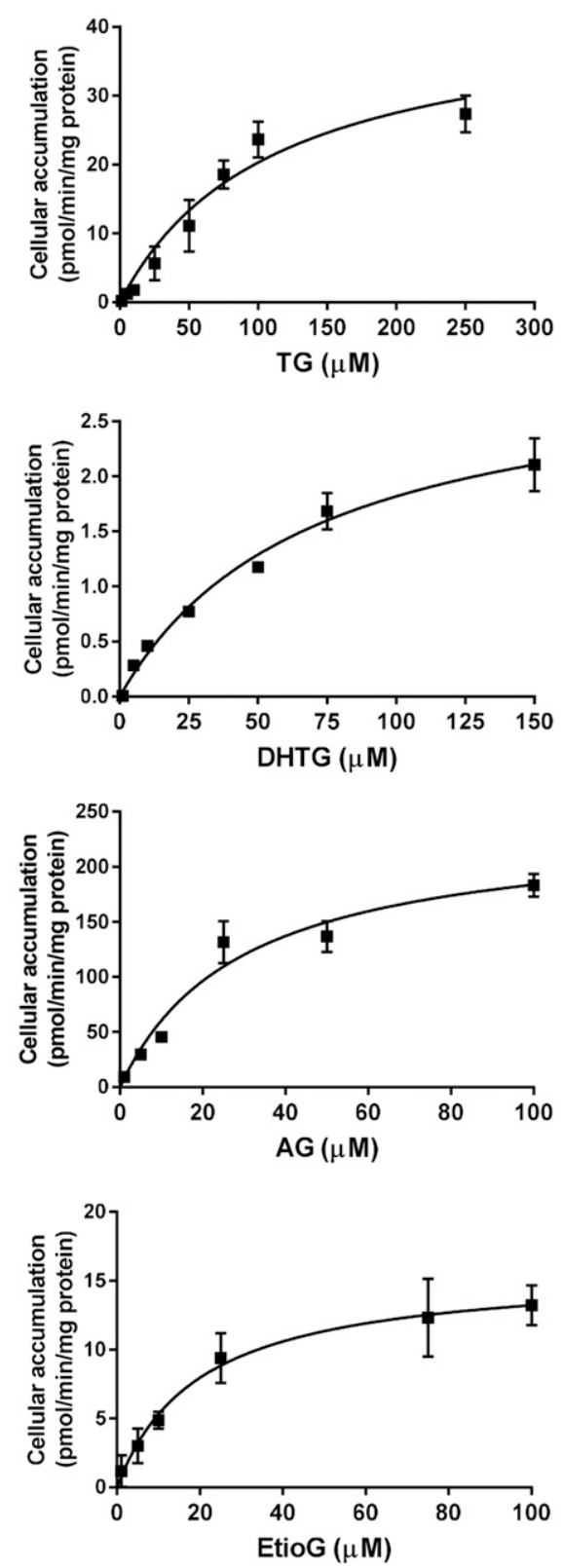

Fig. 2. Uptake kinetics of TG (A), DHTG (B), AG (C), and EtioG (D) in HEK293 cell lines overexpressing OATP1B1 (left panel) or OATP1B3 (right panel). The kinetic experiments were conducted at various concentrations ranging from 1 to $500 \mu \mathrm{M}$ for 5 minutes. The uptake data of the studied glucuronides in OATP-overexpressing cells and the MOCK cells were presented in Supplemental Fig. 1. The OATP-mediated net uptake, calculated by subtracting the uptake in HEK293 MOCK from that in HEK293 OATPoverexpressing cells, was used for the MichaelisMenten fit $\left[\nu=V_{\mathrm{max}^{*}}[\mathrm{~S}] /\left([\mathrm{S}]+K_{\mathrm{m}}\right)\right]$. The kinetic constants $\left(V_{\max }\right.$ and $K_{\mathrm{m}}$ with the $95 \% \mathrm{CI}$ ) for the studied glucuronide metabolites and transporters are presented in Table 1 . All incubations for uptake studies were performed in triplicates $(n=3)$.
OATP1B1 substrate drugs (Mwinyi et al., 2004; Maeda, 2015). In OATP1B3, there are two mutations (c.334T $>$ G and c.699G $>$ A) that are frequently observed and exhibit different transport efficiencies. A decreased clearance of docetaxel was observed in patients with nasopharyngeal carcinoma and c.699G $>\mathrm{A}$ allele (Chew et al., 2012). Because testosterone is a lipophilic compound, passive diffusion was originally thought to be the only mechanism of testosterone transport across the cell membrane (Srinivas-Shankar and $\mathrm{Wu}, 2006$ ). However, later studies confirmed that OATP1B3 is also involved in the uptake of testosterone in human prostatic tissue (Hamada et al., 2008; Kaipainen et al., 2019). Particularly, OATP1B3 has been shown to transport testosterone in Cos-7 cells transfected with wild-type, heterozygous variants $(334 \mathrm{G}$ or 699A), whereas the transport of testosterone was completely abolished in the double mutant (GG/AA) (Hamada et al., 2008).
No evidence of the role of hepatic OATP1B3 in testosterone transport is shown. OATP1B3 was found markedly overexpressed in prostatic cancer tissues as compared with healthy subjects, and OATP1B3 double mutant in patients with prostate cancer was associated with longer survival. OOur results provide new information that the major circulating metabolites of testosterone, including TG, AG, DHTG, and EtioG, are substrates of OATP1B1 and OATP1B3 (Fig. 1B). It is possible that genetic polymorphisms in OATPs could alter the transport of androgen glucuronides and consequently contribute to the large interindividual variation in the circulating concentrations of testosterone. The present study is the first study that elucidates the mechanisms of hepatic uptake of androgen glucuronides. Whether genetic variations in OATP genes influence the concentration of androgen glucuronides remains to be studied from clinical studies. 
TABLE 1

Kinetic parameters $\left(K_{\mathrm{m}}\right.$ and $\left.V_{\max }\right)$ for active uptake of major testosterone glucuronides (TG, DHTG, AG, and EtioG) by OATP1B1 and OATP1B3 The kinetic parameters were derived from experimental data in Fig. 2, after fitting the MichaelisMenten equations. The 95\% CIs for the derived kinetic constants are presented in the parentheses. All incubations for uptake studies were performed in triplicates $(n=3)$.

\begin{tabular}{|c|c|c|c|c|}
\hline \multirow[b]{2}{*}{ Substrate } & \multicolumn{2}{|r|}{ OATP1B1 } & \multicolumn{2}{|r|}{ OATP1B3 } \\
\hline & $\begin{array}{l}K_{\mathrm{m}}, \mu \mathrm{M} \\
(95 \% \mathrm{CI})\end{array}$ & $V_{\max }, \mathrm{pmol} / \min$ per milligram protein & $\begin{array}{l}K_{\mathrm{m}}, \mu \mathrm{M} \\
(95 \% \mathrm{CI})\end{array}$ & $V_{\max }, \mathrm{pmol} / \mathrm{min}$ per milligram protein \\
\hline TG & $\begin{array}{c}56.71 \\
(44.81-71.09)\end{array}$ & $\begin{array}{c}3.89 \\
(3.58-4.23)\end{array}$ & $\begin{array}{c}110.4 \\
(70.3-177.3)\end{array}$ & $\begin{array}{c}42.72 \\
(34.23-55.22)\end{array}$ \\
\hline DHTG & $\begin{array}{c}71.27 \\
(55.37-90.8)\end{array}$ & $\begin{array}{c}1.21 \\
(1.10-1.33)\end{array}$ & $\begin{array}{c}69.57 \\
(49.1-101.1)\end{array}$ & $\begin{array}{c}3.08 \\
(2.64-3.70)\end{array}$ \\
\hline $\mathrm{AG}$ & $\begin{array}{c}46.18 \\
(26.11-93.83)\end{array}$ & $\begin{array}{c}44.05 \\
(34.21-64.9)\end{array}$ & $\begin{array}{c}29.27 \\
(18.04-48.9)\end{array}$ & $\begin{array}{c}237.5 \\
(194.9-298.7)\end{array}$ \\
\hline EtioG & $\begin{array}{c}6.16 \\
(2.95-12.32)\end{array}$ & $\begin{array}{c}2.32 \\
(1.95-2.73)\end{array}$ & $\begin{array}{c}19.81 \\
(11.45-35)\end{array}$ & $\begin{array}{c}15.84 \\
(13.42-19.16)\end{array}$ \\
\hline
\end{tabular}

Although our results indicate that the major testosterone glucuronide metabolites are not substrates of OATP2B1 (Fig. 1A), genetic variation in OATP2B1 (A $>\mathrm{G}, \mathrm{rs} 12422149)$ has been associated with decreased circulating levels of testosterone and DHT after administration of $500 \mathrm{mg}$ testosterone enanthate (Schulze et al., 2012). OATP2B1 G-allele carriers also appear to have increased risk of prostate cancer-specific mortality (Wright et al., 2011). This could be due to the higher uptake of dehydroepiandrosterone-sulfate
(DHEAS) by OATP2B1 in prostatic tissues, as OATP2B1 has been reported to mediate the transport of steroid conjugates such as DHEAS and estrone-3-sulfate (Yang et al., 2011). DHEAS is a weak androgen and is also the precursor of testosterone; the increased uptake of DHEAS could lead to lower levels of testosterone and its metabolites remaining in the circulation. It is known that OATP2B1-mediated transport is pH-dependent. For example, Varma et al. (2011) reported that acidic extracellular $\mathrm{pH}$ increases OATP2B1

TABLE 2

Quantitative parameters applied for In vitro to in vivo extrapolation scaling The intrinsic clearances of TG, AG, EtioG, and DHTG $\left(C L_{\text {int }}\right.$, microliters per minute per picomole transporter protein) were characterized from transport kinetics parameters and normalized by transporter abundance. The protein abundance of uptake transporters (OATP1B1 and OATP1B3) was quantified by quantitative proteomics in HEK293 OATP-overexpressing cell lines and human liver tissues $(n=3)$. Liver TMPPGT was experimentally derived in-house.

\begin{tabular}{|c|c|c|c|}
\hline System & Parameters & OATP1B1 & OATP1B3 \\
\hline HEK293 OATP-overexpressing cell & \multicolumn{3}{|c|}{$V_{\text {max,cells }}($ pmol substrate/min per milligram protein) } \\
\hline \multirow{20}{*}{ line } & TG & 3.89 & 42.72 \\
\hline & AG & 44.05 & 237.5 \\
\hline & EtioG & 2.32 & 15.84 \\
\hline & DHTG & 1.21 & 3.08 \\
\hline & \multicolumn{3}{|l|}{$K_{\mathrm{m}, \text { cells }}(\mu \mathrm{M})$} \\
\hline & TG & 56.71 & 110.4 \\
\hline & AG & 46.18 & 29.27 \\
\hline & EtioG & 6.16 & 19.81 \\
\hline & DHTG & 71.27 & 69.57 \\
\hline & $\begin{array}{c}\text { Transporter abundance }\left(\mathrm{E}_{\text {cell }}, \text { pmol transporter } / \mathrm{mg}\right. \\
\text { protein })\end{array}$ & 6.86 & 7.42 \\
\hline & \multicolumn{3}{|c|}{ Clearance $\left(C L_{\text {int,cell }}, \mu \mathrm{l} / \mathrm{min}\right.$ per picomole transporter $)=V_{\text {max,cell }} / K_{\mathrm{m}, \text { cell }} / \mathrm{E}_{\text {cell }}$} \\
\hline & TG & 0.01 & 0.05 \\
\hline & $\mathrm{AG}$ & 0.14 & 1.09 \\
\hline & EtioG & 0.05 & 0.11 \\
\hline & DHTG & 0.002 & 0.01 \\
\hline & Fractional contribution of individual transporter $\left(f_{t}\right)$ & OATP1B1 & OATP1B3 \\
\hline & TG & 0.16 & 0.84 \\
\hline & AG & 0.11 & 0.89 \\
\hline & EtioG & 0.34 & 0.66 \\
\hline & DHTG & 0.29 & 0.71 \\
\hline \multirow[t]{13}{*}{ Liver } & $\begin{array}{c}\text { Transporter abundance }\left(\mathrm{E}_{\text {liver }} \text {, pmol transporter/mg }\right. \\
\text { protein) }\end{array}$ & 3.64 & 1.49 \\
\hline & TM-PPGT (mg protein/gram of tissue) & 49.40 & 49.40 \\
\hline & Tissue weight $(\mathrm{kg})$ & 1.60 & 1.60 \\
\hline & \multicolumn{3}{|c|}{ Estimated hepatic clearance $\left(C L_{\text {int, } \mu l / \text { min }}\right)=C l_{\text {int,cell }} * \mathrm{E}_{\text {liver, total }}$} \\
\hline & TG & 2875 & 6142 \\
\hline & AG & 39,976 & 128,786 \\
\hline & EtioG & 15,742 & 12,691 \\
\hline & DHTG & 714 & 703 \\
\hline & \multicolumn{3}{|l|}{ Fractional contribution of individual transporter $\left(f_{t}\right)$} \\
\hline & TG & 0.32 & 0.68 \\
\hline & AG & 0.24 & 0.76 \\
\hline & EtioG & 0.55 & 0.45 \\
\hline & DHTG & 0.50 & 0.50 \\
\hline
\end{tabular}



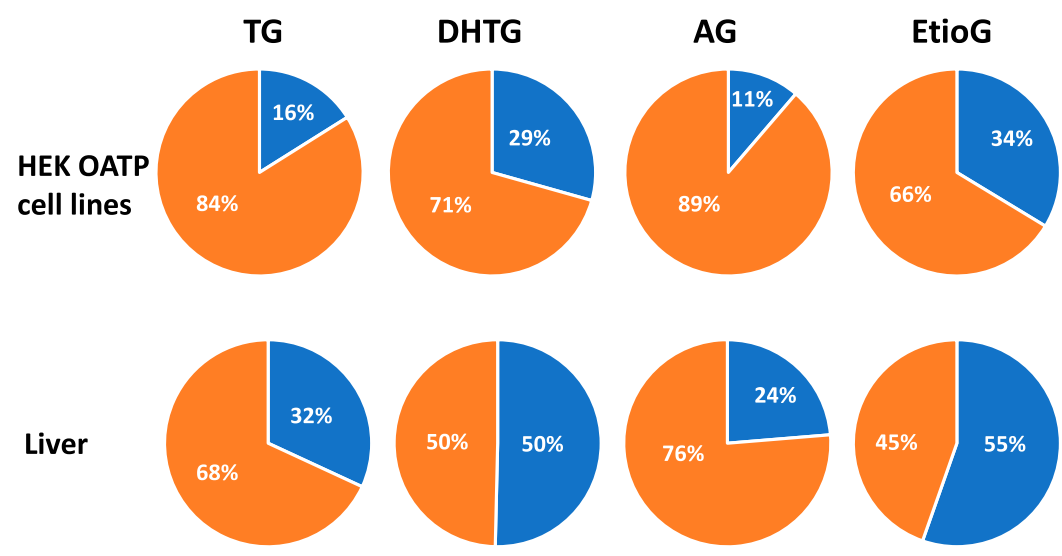

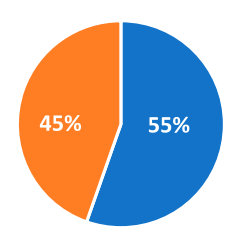

\section{OATP1B1}

OATP1B3
Fig. 3. Fractional contribution of uptake transporter OATP1B1 and OATP1B3 to the clearance of TG, DHTG, AG, and EtioG in HEK293 OATP-overexpressing cell lines and in human liver tissue after integrating the scaling factor. The individual scaling factors were derived from the relative abundance of the uptake transporters (OATP1B1 and OATP1B3) in human liver vs. that in OATP-overexpressing cells, as shown in Table 2. uptake of various statins in HEK293 OATP2B1-overexpressing cells in comparison with the study conducted at $\mathrm{pH}$ 7.4. Similarly, the uptake rate of estrone-3-sulfate and dehydroepiandrosteronesulfate is 2- to 3 -fold higher at $\mathrm{pH} 5$ than that at $\mathrm{pH} 7.4$ (Nozawa et al., 2004). As the focus of our study was on the endogenous glucuronide metabolites, we performed the uptake studies at physiologically relevant $\mathrm{pH}$ of the sinusoidal hepatic uptake ( $\mathrm{pH}$ 7.4). Although we did not perform the uptake in acidic $\mathrm{pH}$ conditions, our data suggest that OATP2B1 is not involved in the transport of androgen glucuronides at $\mathrm{pH} 7.4$.

Further, OATPs are susceptible to drug-drug interactions (DDIs). Many therapeutically important drugs, such as cyclosporin, gemfibrozil, antibiotics, and antiretroviral drugs, are recognized clinical inhibitors of OATP1B1 (Kalliokoski and Niemi, 2009). For instance, cyclosporine causes up to 20 -fold increase in the area of under the curve of several statin drugs (Regazzi et al., 1993; Maeda, 2015). Therefore, coadministration of testosterone with drugs that are known OATP1B1 or OATP1B3 inhibitors may lead to DDIs or adverse drug reactions.
Thus, assessing OATP-mediated DDI potential during testosterone dosage may be necessary.

Moreover, since TG is a relatively selective substrate of OATP1B3 (Fig. 3), it can be tested to distinguish drug interaction with OATPs. Recently, coproporphyrins I and II are the gold-standard clinical biomarkers of OATP function; however, these markers cannot distinguish OATP1B1 and OATP1B3 contributions. In the present study, we showed that TG and AG are predominantly transported by OATP1B3 with a minor contribution from OATP1B1, indicating TG and AG could be used as potential endogenous biomarkers to predict OATP1B3-mediated drug-drug interactions. Alternatively, the impact of OATP1B3 inhibition may potentially be evaluated by the plasma concentrations of TG and AG. This needs further clinical validation.

Based on human pharmacokinetics studies (West et al., 1951; Sandberg and Slaunwhite, 1956), intravenously administered testosterone is primarily eliminated ( $>70 \%)$ as conjugated metabolites in urine. Although the renal elimination is the key elimination mechanism of androgen glucuronides,

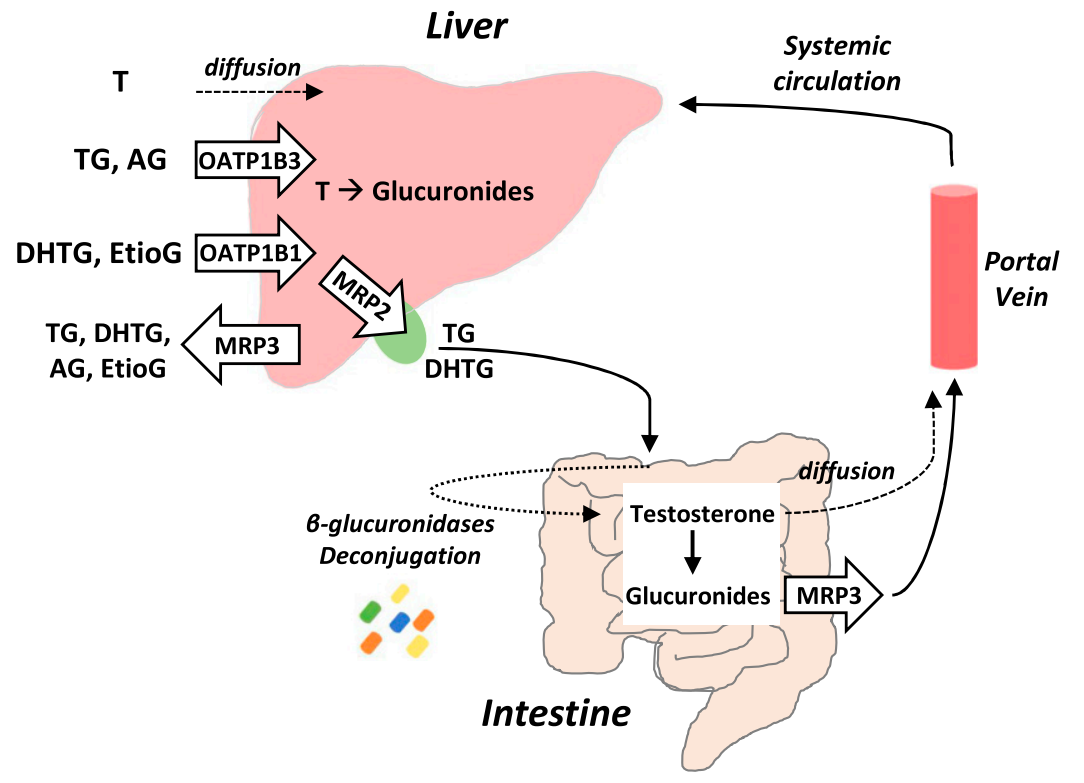

Fig. 4. A proposed disposition model of testosterone and its glucuronide metabolites in liver and intestine. The uptake transporters OATP1B1 and OATP1B3 are expressed in the basolateral side of hepatocyte. Testosterone (T) could be either passively diffused (Srinivas-Shankar and $\mathrm{Wu}, 2006$ ) or actively transported by OATP1B3 into human livers (Hamada et al., 2008). In both liver and intestine, testosterone could be metabolized by UGT2B17 and UGT2B15 to form glucuronide metabolites (Basit et al., 2018). In liver, the generated glucuronide metabolites are effluxed by MRP2 into bile or by MRP3 back into systemic circulation. In the intestinal lumen, the biliary-excreted glucuronides can be hydrolyzed or deconjugated by gut bacterial $\beta$-glucuronidases, which recycles testosterone via enterohepatic circulation, whereas glucuronides formed in the intestine are effluxed by MRP3 and enter systemic circulation via portal vein ( $\mathrm{Li}$ et al., 2019). 
the hepatic uptake and subsequent enterohepatic recycling likely play a crucial role in increasing the distribution and half-lives of androgens. The enterohepatic recycling allows for reactivation of active androgen that can increase their physiologic levels and activity. Although a significant fraction of the dose is eliminated through bile, only about $6 \%$ is recovered in the stool. In animals, bile duct cannulation studies suggest that up to $75 \%$ of the conjugated testosterone is eliminated in bile (Barry et al., 1952; Ashmore et al., 1953; Matsui et al., 1975; Yamamoto et al., 1978a,b). Although the data are limited, the biliary excretion of testosterone and its metabolites in humans seems to differ from that observed in animal species. In contrast to humans, animals (rats, mice, and dogs) excrete most of the administered testosterone in the bile and very little in the urine (Paschkis et al., 1944; Barry et al., 1952; Ashmore et al., 1953). Further clinical investigations are needed to better quantify the role of enterohepatic recycling in testosterone disposition in human and delineate the species differences. Collectively, these data suggest that a large fraction of biliary-excreted testosterone glucuronides are deconjugated likely via gut $\beta$-glucuronidase and reabsorbed. Although the biliary-excreted fraction is not detected in feces and eventually is eliminated into the urine, our data suggest that OATPs are important mechanisms that influence distribution and half-lives of androgen glucuronides. Therefore, although renal elimination is a major mechanism for testosterone glucuronide elimination, hepatic uptake of the glucuronide metabolites is critical for the activation of testosterone. Since testosterone glucuronide is 20 to 80 -fold higher in the plasma as compared with testosterone (Basit et al., 2018), even a minor fraction (e.g., 10\%) of a hepatically eliminated fraction can lead to a significant increase (e.g., 2- to 4-fold) in the active testosterone after recycling. Furthermore, testosterone is an important drug, and testosterone replacement therapy using the oral route is a crucial unmet need. Therefore, the findings presented in the present study are important for the interpretation of oral pharmacokinetics of testosterone and the prediction of drugtestosterone interactions.

In summary, the present study together with our previously identified efflux mechanism of androgen glucuronides ( $\mathrm{Li}$ et al., 2019) provides new insight into the mechanisms of androgen disposition. It would be of interest to further study the genetic variation of OATPs and MRPs on the disposition of androgen glucuronides in patients with or without prostate cancer, as well as in the context of genetic testing for doping. Although glomerular filtration is a likely mechanism of renal elimination of androgen glucuronides, the role of renal organic anion transporters needs to be investigated to completely understand their overall disposition. Nevertheless, the fractional contribution of uptake and efflux transporters characterized in our studies would be important for predicting androgen disposition and drug-androgen interactions in humans.

\section{Acknowledgments}

The authors would like to thank Abdul Basit and Yuanyuan Shi, Department of Pharmaceutics, University of Washington, for technical assistance with LC-MS/MS measurement of studied glucuronide metabolites.

\section{Authorship Contributions}

Participated in research design: Li, Gupta, Prasad.

Conducted experiments: Li, Gáborik, Kis.
Contributed new reagents or analytic tools: Gáborik, Kis. Performed data analysis: Li, Gáborik, Kis, Prasad.

Wrote or contributed to the writing of the manuscript: Li, Gupta, Gáborik, Kis, Prasad.

\section{References}

Álvarez AI, Vallejo F, Barrera B, Merino G, Prieto JG, Tomás-Barberán F, and Espín JC (2011) Bioavailability of the glucuronide and sulfate conjugates of genistein and daidzein in breast cancer resistance protein 1 knockout mice. Drug Metab Dispos 39:2008-2012.

Ashmxc1cccore J, Elliott WH, Doisy EA Jr., and Doisy EA (1953) Excretion of the metabolites of testosterone-4-C14 in the rat. J Biol Chem 200:661-668.

Barry MC, Eidinoff ML, Dobriner K, and Gallagher TF (1952) The fate of C14 testosterone and C14-progesterone in mice and rats. Endocrinology 50:587-599.

Basit A, Amory JK, and Prasad B (2018) Effect of dose and $5 \alpha$-reductase inhibition on the circulating testosterone metabolite profile of men administered oral testosterone. Clin Transl Sci 11:513-522.

Bhasin S, Cunningham GR, Hayes FJ, Matsumoto AM, Snyder PJ, Swerdloff RS, and Montori VM (2006) Testosterone therapy in adult men with androgen deficiency syndromes: an endocrine society clinical practice guideline. J Clin Endocrinol Metab 91:1995-2010.

Bhasin S, Cunningham GR, Hayes FJ, Matsumoto AM, Snyder PJ, Swerdloff RS, and Montori VM; Task Force, Endocrine Society (2010) Testosterone therapy in men with androgen deficiency syndromes: an Endocrine Society clinical practice guideline. J Clin Endocrinol Metab 95:2536-2559.

Bhasin S and Matsumoto AM (2010) Patient information page from the hormone foundation. Patient guide to testosterone therapy in adult men with androgen deficiency syndromes. J Clin Endocrinol Metab 95:2p following 3085.

Bhatt DK and Prasad B (2018) Critical issues and optimized practices in quantification of protein abundance level to determine interindividual variability in DMET proteins by LC-MS/MS proteomics. Clin Pharmacol Ther 103:619-630.

Brand W, Oosterhuis B, Krajcsi P, Barron D, Dionisi F, van Bladeren PJ, Rietjens IM, and Williamson G (2011) Interaction of hesperetin glucuronide conjugates with human BCRP, MRP2 and MRP3 as detected in membrane vesicles of overexpressing baculovirus-infected Sf9 cells. Biopharm Drug Dispos 32: $530-535$.

Carr DF, O’Meara H, Jorgensen AL, Campbell J, Hobbs M, McCann G, van Staa T, and Pirmohamed M (2013) SLCO1B1 genetic variant associated with statininduced myopathy: a proof-of-concept study using the clinical practice research datalink. Clin Pharmacol Ther 94:695-701.

Chew SC, Sandanaraj E, Singh O, Chen X, Tan EH, Lim WT, Lee EJ, and Chowbay B (2012) Influence of SLCO1B3 haplotype-tag SNPs on docetaxel disposition in Chinese nasopharyngeal cancer patients. Br J Clin Pharmacol 73:606-618.

Chu X, Chan GH, and Evers R (2017) Identification of endogenous biomarkers to predict the propensity of drug candidates to cause hepatic or renal transportermediated drug-drug interactions. J Pharm Sci 106:2357-2367.

González-Sarrías A, Giménez-Bastida JA, Núñez-Sánchez MA, Larrosa M, GarcíaConesa MT, Tomás-Barberán FA, and Espín JC (2014) Phase-II metabolism limits the antiproliferative activity of urolithins in human colon cancer cells. Eur J Nutr 53:853-864.

Hamada A, Sissung T, Price DK, Danesi R, Chau CH, Sharifi N, Venzon D, Maeda K, Nagao K, Sparreboom A, et al. (2008) Effect of SLCO1B3 haplotype on testosterone transport and clinical outcome in caucasian patients with androgen-independent prostatic cancer. Clin Cancer Res 14:3312-3318.

Heikkilä R, Aho K, Heliövaara M, Hakama M, Marniemi J, Reunanen A, and Knekt P (1999) Serum testosterone and sex hormone-binding globulin concentrations and the risk of prostate carcinoma: a longitudinal study. Cancer 86:312-315.

Jarvis TR, Chughtai B, and Kaplan SA (2015) Testosterone and benign prostatic hyperplasia. Asian J Androl 17:212-216.

Kaipainen A, Zhang A, Gil da Costa RM, Lucas J, Marck B, Matsumoto AM, Morrissey C, True LD, Mostaghel EA, and Nelson PS (2019) Testosterone accumulation in prostate cancer cells is enhanced by facilitated diffusion. Prostate 79:1530-1542.

Kalliokoski A and Niemi M (2009) Impact of OATP transporters on pharmacokinetics. Br J Pharmacol 158:693-705.

Li CY, Basit A, Gupta A, Gáborik Z, Kis E, and Prasad B (2019) Major glucuronide metabolites of testosterone are primarily transported by MRP2 and MRP3 in human liver, intestine and kidney. J Steroid Biochem Mol Biol 191:105350.

Link E, Parish S, Armitage J, Bowman L, Heath S, Matsuda F, Gut I, Lathrop M, and Collins R; SEARCH Collaborative Group (2008) SLCO1B1 variants and statininduced myopathy--a genomewide study. N Engl J Med 359:789-799.

Maeda K (2015) Organic anion transporting polypeptide (OATP)1B1 and OATP1B3 as important regulators of the pharmacokinetics of substrate drugs. Biol Pharm Bull 38:155-168.

Matsui M, Kinuyama Y, and Hakozaki M (1975) Metabolism of testosterone sulfate in the rat: analysis of biliary metabolites. Steroids 25:637-648.

Mauvais-Jarvis P, Floch HH, and Bercovici JP (1968) Studies on testosterone metabolism in human subjects with normal and pathological sexual differentiation. $J$ Clin Endocrinol Metab 28:460-471.

McBride JA, Carson CC III, and Coward RM (2016) Testosterone deficiency in the aging male. Ther Adv Urol 8:47-60.

Mwinyi J, Johne A, Bauer S, Roots I, and Gerloff T (2004) Evidence for inverse effects of OATP-C (SLC21A6) 5 and 1b haplotypes on pravastatin kinetics. Clin Pharmacol Ther 75:415-421.

Nozawa T, Imai K, Nezu J, Tsuji A, and Tamai I (2004) Functional characterization of $\mathrm{pH}$-sensitive organic anion transporting polypeptide OATP-B in human. J Pharmacol Exp Ther 308:438-445.

Paschkis KE, Cantarow A, Rakoff AE, Hansen L, and Walkling AA (1944) Excretion in the dog of androgens and estrogens in the bile following injections of androgens. Proc Soc Exp Biol Med 55:127-130. 
Patel KR, Andreadi C, Britton RG, Horner-Glister E, Karmokar A, Sale S, Brown VA, Brenner DE, Singh R, Steward WP, et al. (2013) Sulfate metabolites provide an intracellular pool for resveratrol generation and induce autophagy with senescence. Sci Transl Med 5:205ra133.

Prasad B, Achour B, Artursson P, Hop CECA, Lai Y, Smith PC, Barber J, Wisniewski JR, Spellman D, Uchida Y, et al. (2019) Toward a consensus on applying quantitative liquid chromatography-tandem mass spectrometry proteomics in translational pharmacology research: a white paper. Clin Pharmacol Ther 106:525-543.

Prasad B, Bhatt DK, Johnson K, Chapa R, Chu X, Salphati L, Xiao G, Lee C, Hop CECA, Mathias A, et al. (2018) Abundance of phase 1 and 2 drug-metabolizing enzymes in alcoholic and hepatitis C cirrhotic livers: a quantitative targeted proteomics study. Drug Metab Dispos 46:943-952.

Prasad B, Gaedigk A, Vrana M, Gaedigk R, Leeder JS, Salphati L, Chu X, Xiao G, Hop C, Evers R, et al. (2016) Ontogeny of hepatic drug transporters as quantified by LC-MS/MS proteomics. Clin Pharmacol Ther 100:362-370.

Regazzi MB, Iacona I, Campana C, Raddato V, Lesi C, Perani G, Gavazzi A, and Viganò M (1993) Altered disposition of pravastatin following concomitant drug therapy with cyclosporin A in transplant recipients. Transplant Proc 25 2732-2734.

Sandberg AA and Slaunwhite WR Jr. (1956) Metabolism of 4-C14-testosterone in human subjects. I. Distribution in bile, blood, feces and urine. J Clin Invest 35:1331-1339.

Saudan C, Baume N, Robinson N, Avois L, Mangin P, and Saugy M (2006) Testosterone and doping control. Br J Sports Med 40 (Suppl 1):i21-i24.

Schlich C and Romanelli F (2016) Issues surrounding testosterone replacement therapy. Hosp Pharm 51:712-720.

Schulze JJ, Johansson M, Rane A, and Ekstrom L (2012) Genetic variation in SLCO2B1 is associated with serum levels of testosterone and its metabolites prior to and two days after testosterone administration. Curr Pharmacogenomics Person Med (10):226-230.

Srinivas-Shankar U and Wu FC (2006) Drug insight: testosterone preparations. Nat Clin Pract Urol 3:653-665.

Tenover JS (1992) Effects of testosterone supplementation in the aging male. J Clin Endocrinol Metab 75:1092-1098.

Traish AM (2016) Testosterone therapy in men with testosterone deficiency: are the benefits and cardiovascular risks real or imagined? Am J Physiol Regul Integr Comp Physiol 311:R566-R573.

Ugwu ET and Ikem RT (2018) Androgen deficiency in aging male questionnaire for the clinical detection of testosterone deficiency in a population of black sub-saharan African men with type 2 diabetes mellitus: is it a reliable tool? Curr Diabetes Rev 14:280-285.

Varma MV, Rotter CJ, Chupka J, Whalen KM, Duignan DB, Feng B, Litchfield J, Goosen TC, and El-Kattan AF (2011) pH-sensitive interaction of HMG-CoA reductase inhibitors (statins) with organic anion transporting polypeptide $2 \mathrm{~B} 1$. Mol Pharm 8:1303-1313.

Voora D, Shah SH, Spasojevic I, Ali S, Reed CR, Salisbury BA, and Ginsburg GS (2009) The SLCO1B1*5 genetic variant is associated with statin-induced side effects. J Am Coll Cardiol 54:1609-1616.

West CD, Tyler FH, Brown H, and Samuels LT (1951) The role of the liver and kidneys in the metabolism of intravenous testosterone by human subjects. $J$ Clin Endocrinol Metab 11:897-912.

Wright JL, Kwon EM, Ostrander EA, Montgomery RB, Lin DW, Vessella R, Stanford JL, and Mostaghel EA (2011) Expression of SLCO transport genes in castrationresistant prostate cancer and impact of genetic variation in SLCO1B3 and SLCO2B1 on prostate cancer outcomes. Cancer Epidemiol Biomarkers Prev 20: 619-627.

Yamamoto Y, Manyon A, Kirdani RY, and Sandberg AA (1978a) Androgen metabolism in the rhesus monkey. Steroids 31:711-729.

Yamamoto Y, Osawa Y, Kirdani RY, and Sandberg AA (1978b) Testosterone metabolites in dog bile. Steroids 31:233-247.

Yang M, Xie W, Mostaghel E, Nakabayashi M, Werner L, Sun T, Pomerantz M, Freedman M, Ross R, Regan M, et al. (2011) SLCO2B1 and SLCO1B3 may determine time to progression for patients receiving androgen deprivation therapy for prostate cancer. J Clin Oncol 29:2565-2573.

Zhang H, Basit A, Busch D, Yabut K, Bhatt DK, Drozdzik M, Ostrowski M, Li A, Collins C, Oswald S, et al. (2018) Quantitative characterization of UDPglucuronosyltransferase $2 \mathrm{~B} 17$ in human liver and intestine and its role in testosterone first-pass metabolism. Biochem Pharmacol 156:32-42.

Zimmerman EI, Hu S, Roberts JL, Gibson AA, Orwick SJ, Li L, Sparreboom A and Baker SD (2013) Contribution of OATP1B1 and OATP1B3 to the disposition of sorafenib and sorafenib-glucuronide. Clin Cancer Res 19:1458-1466.

Address correspondence to: Dr. Bhagwat Prasad, Department of Pharmaceutical Sciences, Washington State University, 412 E Spokane Falls Blvd, Spokane, WA 99202. E-mail: bhagwat.prasad@wsu.edu 